\title{
Sea Level Rise, from Global to Local
}

Planet Earth is currently in a state of energy imbalance: it reemits less energy to space than it receives from the sun. This energy imbalance is estimated to be on the order of $1 \mathrm{Watt} / \mathrm{m}^{2}$, a quantity small compared to the $342 \mathrm{Watts} / \mathrm{m}^{2}$ received from the sun on the spherical planet, but significant enough to cause important changes of the global climate. The cause of this energy imbalance is well known and attributed to greenhouse gas (GHG) emitted by human activities, mostly carbon dioxide $\left(\mathrm{CO}_{2}\right)$ as a result of fossil fuel combustion and land use change (mostly deforestation). GHG absorb part of the infrared radiations emitted by the Earth causing an additional greenhouse effect that superimposes on the natural greenhouse effect.

Over the decade 2009-2018, emissions in $\mathrm{CO}_{2}$ equivalent from fossil fuels and deforestation amount to 37.5 and $5.5 \mathrm{Gt} /$ year respectively (Global Carbon Budget project, Friedlingstein, 2019). Only $44 \%$ have stayed in the atmosphere because of two important sinks: the vegetation and the oceans that absorbed respectively $29 \%$ and $23 \%$ of emitted $\mathrm{CO}_{2}$. However, a negative impact of the ocean sink is acidification of sea water, with potential disastrous consequences on marine life and marine ecosystems. The $\mathrm{CO}_{2}$ concentration in the atmosphere has reached 410 ppm (parts per million) in 2019, a value $40 \%$ higher than the highest concentrations encountered by planet Earth during the last 800,000 years.

Over the past 50 years, about $93 \%$ of the energy excess due to human activities has been stored as heat into the ocean (von Schuckmann et al., 2016). This is so because the ocean has the largest thermal inertia of all compartments of the climate system. The remaining $7 \%$, are equally shared to warm the atmosphere and the continents, and melt sea ice and land ice.

Warming of the ocean and melting of land ice (glaciers, and Greenland and Antarctica ice sheets) have another consequence: sea level rise.

After the $\sim 130 \mathrm{~m}$ sea level rise associated with the last deglaciation that started about 20,000 years ago, geological, geochemical and archeological observations indicate that the mean sea level remained almost stable during the last 2-3 millennia, then started to rise about 2 centuries ago. A large number of studies have analysed tide gauge data to provide an historical mean sea level time series. These indicate that, over the $20^{\text {th }}$ century, sea level rose by about $15 \mathrm{~cm}$ on average.

Since the early 1990s, satellite altimetry has become the main tool for precisely and continuously measuring sea level with quasi global coverage and a few days revisit time (called the 'orbital cycle'). Compared to tide gauges that provide sea level relative to the ground, satellite altimetry measures 'absolute' sea level variations. High-precision satellite altimetry started with the launch in 1991 of ERS-1 by the European Space Agency (ESA), and in 1992 of the joint NASA (National Aeronautics and Space Administration) - CNES (Centre National d' Etudes Spatiales) satellite Topex/Poseidon (T/P).
Since then, several high-precision altimetry missions have followed: Jason-1 (2001), Jason-2 (2008) and Jason-3 (2016), the successors of T/P with similar orbital characteristics. ESA also developed ERS-2 (1995), Envisat (2002), CryoSat (2010) and Sentinel-3A/3B (2016/2018). Cryosat and Sentinel-3A/3B use new technology, i.e. Synthetic Aperture Radar (SAR) altimetry. The Sentinel-3 missions contribute to the COPERNICUS operational programme of the European Union. SARAL/Altika (2013), a joint Indian-French mission, operates in the Ka-band, allowing smaller radar footprint on ground than other missions.

The global mean sea level (GMSL) is estimated by geographically averaging all sea surface height measurements performed by the satellite during an orbital cycle. Its evolution is deduced from successive orbital cycles. During the past $\sim 27$ years, at least 2 altimeter satellites have been operating simultaneously, and during some periods, even more than 2 . Such data are combined to compute the GMSL change over time. This is shown in Fig.1.

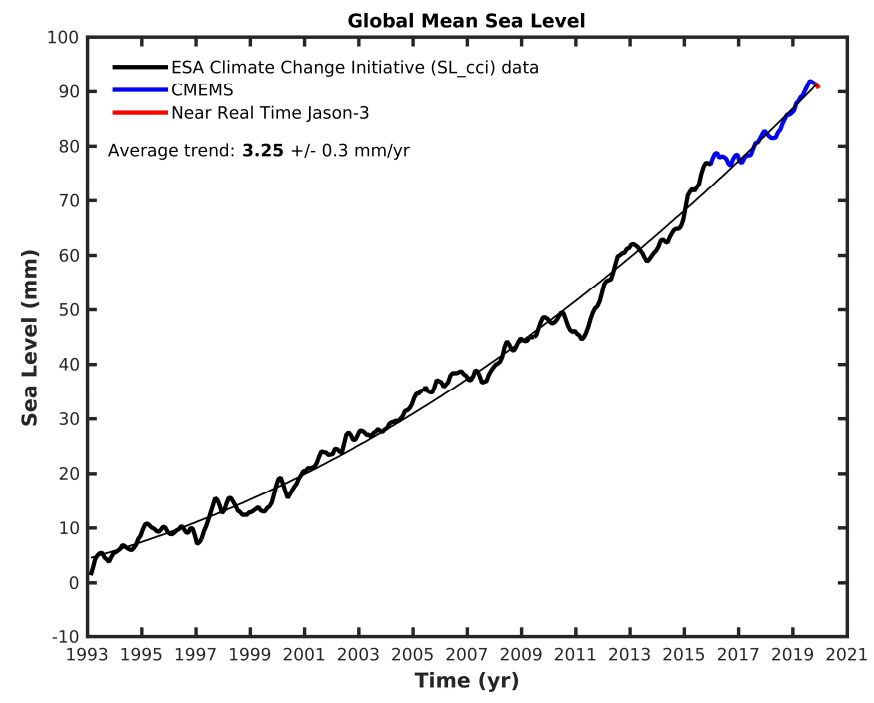

Fig.1. Evolution of the global mean sea level measured by satellite altimetry between January 1993 and April 2020 (source: LEGOS).

The curve shown in Fig. 1 shows that the global mean sea level is rising and even accelerating. Over the period 19932019 , the mean rate of rise is $3.25 \pm 0.3 \mathrm{~mm} / \mathrm{yr}$ (Cazenave et al., 2018, Legeais et al., 2018). The acceleration is estimated to $0.1 \mathrm{~mm} / \mathrm{yr}^{2}$. The precision of a single sea surface height measurement has now reached the 1-2 cm level allowing the precision on the mean rate of rise to reach $\sim 0.3 \mathrm{~mm} / \mathrm{yr}$. This level of precision is also confirmed by comparison with tide gauges and assessments of all sources of errors affecting the altimetry system.

Owing to its quasi global coverage of the oceans, satellite altimetry allows to also map sea level change at regional scale. 


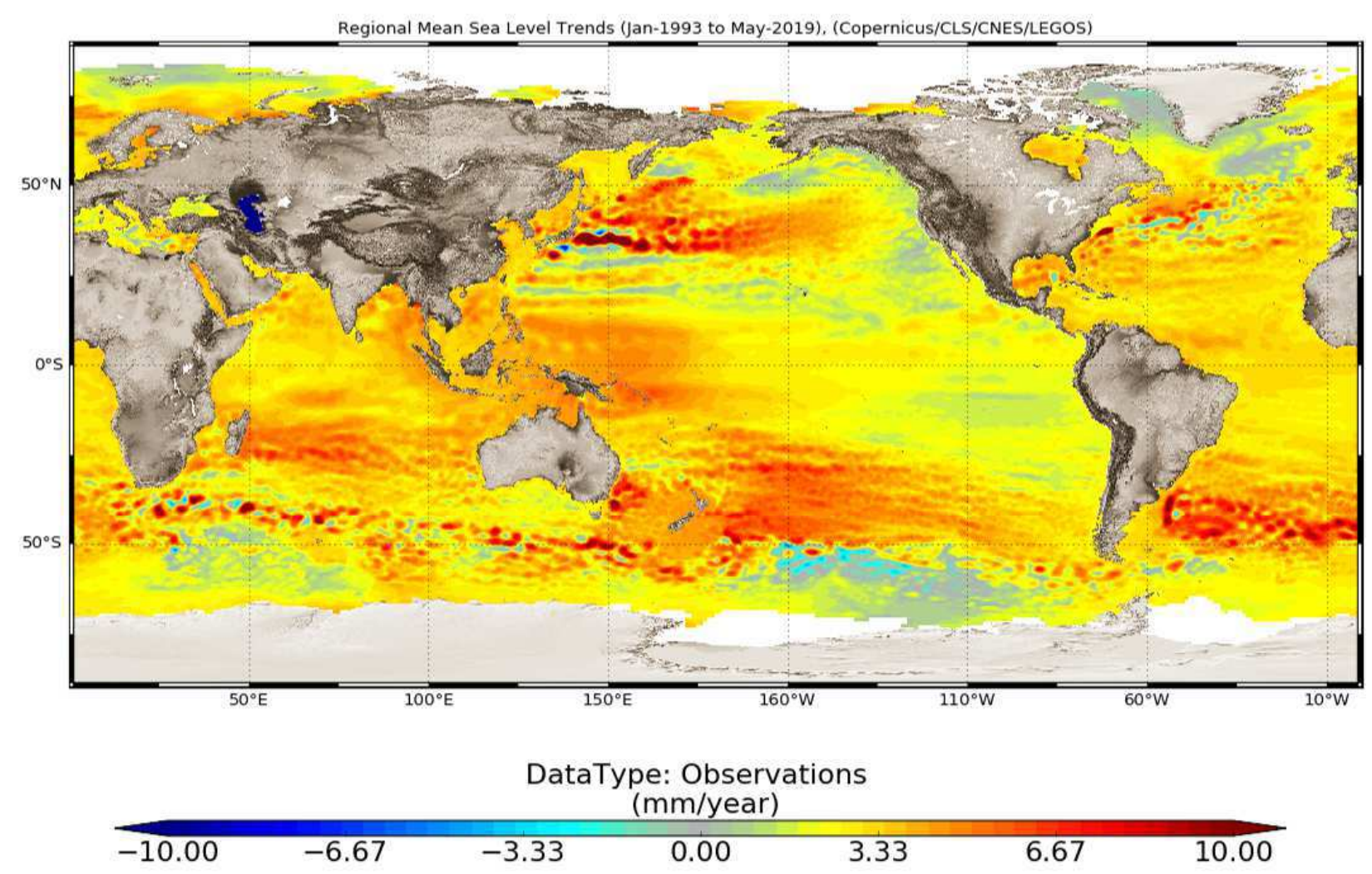

Fig.2. Regional trends (mm/yr) in sea level measured by altimeter satellites since early 1993 (Source: Copernicus Marine Environment Monitoring Service, CMEMS, https://marine.copernicus.eu/)

This is shown in Fig.2. In some regions, sea level trends are 2 to 3 times larger than the global mean rise. This is particularly clear in the northern and western tropical Pacific, as well as in the southern ocean.

\section{Causes of Present-day Global Mean Sea Level Rise}

In terms of global mean, sea level change mostly results from ocean thermal expansion and ocean mass changes due to melting of glaciers and ice mass loss from the Greenland and Antarctica ice sheets. A small contribution comes from changes in land water storage and atmospheric water content. As the oceans warm in response to anthropogenic forcing, sea waters expand, thus sea level rises. When mountain glaciers melt in response to increasing air temperature, sea level rises because of fresh water mass input into the oceans. Similarly, ice mass loss from the ice sheets causes sea level rise. Modification of the land hydrological cycle and associated land water storage due to climate variability and direct anthropogenic forcing also leads to sea level change.

\section{Ocean Warming}

Since the middle of the $20^{\text {th }}$ century, in situ ocean temperature (and to a lesser extent salinity) data have been collected by ships, buoys and moorings, and since the beginning of the 2000s by the automatic profiling floats from the Argo system. During the 1990s, temperature measurements of the upper ocean were collected down to $\sim 700 \mathrm{~m}$ depth along commercial shipping routes. Although the coverage was improved compared to the previous decades, large regions remain un-sampled, in particular in the southern hemisphere and in the Arctic. The Argo project has totally revolutionized the situation, with its $\sim 4000$ automatic floats providing systematic temperature and salinity measure-ments down to $2000 \mathrm{~m}$ depth at 10 day interval, with quasi global coverage. These data have shown that the upper ocean is warming. The associated thermal expansion of sea water is an important contribution to current sea level rise (see below).

\section{Ice Sheets and Glaciers}

If totally melted, Greenland and West Antarctica (the instable part of the continent) would raise sea level by about $7 \mathrm{~m}$ and $5 \mathrm{~m}$ respectively. Thus even a small amount of ice mass loss from the ice sheets can produce substantial sea level rise, with adverse impacts on vulnerable low-lying coastal regions.

Since the early 1990s, different remote sensing observations provide important observations of the mass balance of the ice sheets. These include airborne, satellite-based laser and radar altimetry, Synthetic Aperture Radar Interferometry -InSAR-, and since 2002, space gravimetry from GRACE (Gravity Recovery and Climate Experiment).

It is now well established that the recent ice mass loss partly results from accelerated glacier flow along some coastal margins of the ice sheets and further iceberg discharge into the surrounding ocean. This results from short-term dynamical instabilities occurring in regions where coastal glaciers are grounded below sea level (this is especially the case in West Antarctica). Thinning and subsequent break-up of floating ice tongues or ice shelves that buttressed the glaciers result in rapid 
grounding line retreat and accelerated glacier flow. Several recent observations have also shown that warming of subsurface ocean waters triggers these dynamical instabilities. For Antarctica, this process explains almost all ice mass loss, while for Greenland it only accounts for half, the other half being due to surface melting.

Being very sensitive to global warming, mountain glaciers and small ice caps have retreated worldwide during the $20^{\text {th }}$ century, with significant acceleration since the early 1990s. Volume and mass balance studies of a significant number of glaciers, based on various in situ and remote sensing observing methods and modeling, have been proposed, and estimates of the contribution of glacier melt to sea level rise have been deduced.

\section{Sea Level Budget}

A large number of studies have tried to close the sea level budget, i.e. compare the observed rate of sea level rise with the sum of contributions estimated independently (e.g., the WCRP sea level budget, 2018, Nerem et al., 2018). Studying closure (or non-closure) of the sea level budget is important as it provides constraints on missing or poorly known contributions such as the deep ocean under-sampled by current observing systems, or on still uncertain changes in water storage on land due to human activities (e.g., groundwater depletion in aquifers). Global mean sea level corrected for ocean mass change allows one to independently estimate changes in total ocean heat content over time, from which the Earth's energy imbalance can be deduced.

Figure 3 shows time series of individual components to the global mean sea level as well as the sum of components compared to the observed global mean sea level over 1993present. One can see that the sea level budget is almost closed over the study period within respective error bars. Annual residuals remain below the $2 \mathrm{~mm}$ level. In terms of trends, the sea level budget since 2005 is closed to better than $0.3 \mathrm{~mm} / \mathrm{yr}$, an order of magnitude similar to the mean sea level rise uncertainty. Quasi closure of the budget over the altimetry era suggests that any non-assessed component (i.e., deep ocean heat content below 2000m) does not yet significantly contribute to the global mean sea level rise. Besides, this indicates that no systematic errors affect the different observing systems used to quantify the components of the sea level budget.

\section{Regional and Local Sea Level Changes}

The regional variability in sea level trends is mainly due to large-scale changes in temperature and salinity-related density structure of the oceans, in response to forcing factors (e.g., heat and fresh water exchange at the sea-air interface and wind stress) and their interaction with the ocean circulation. Increase in wind stress and associated deepening of the thermocline explain the strong sea level trends observed in the western tropical Pacific during the altimetry era.

At local scales, in particular, in coastal areas, additional

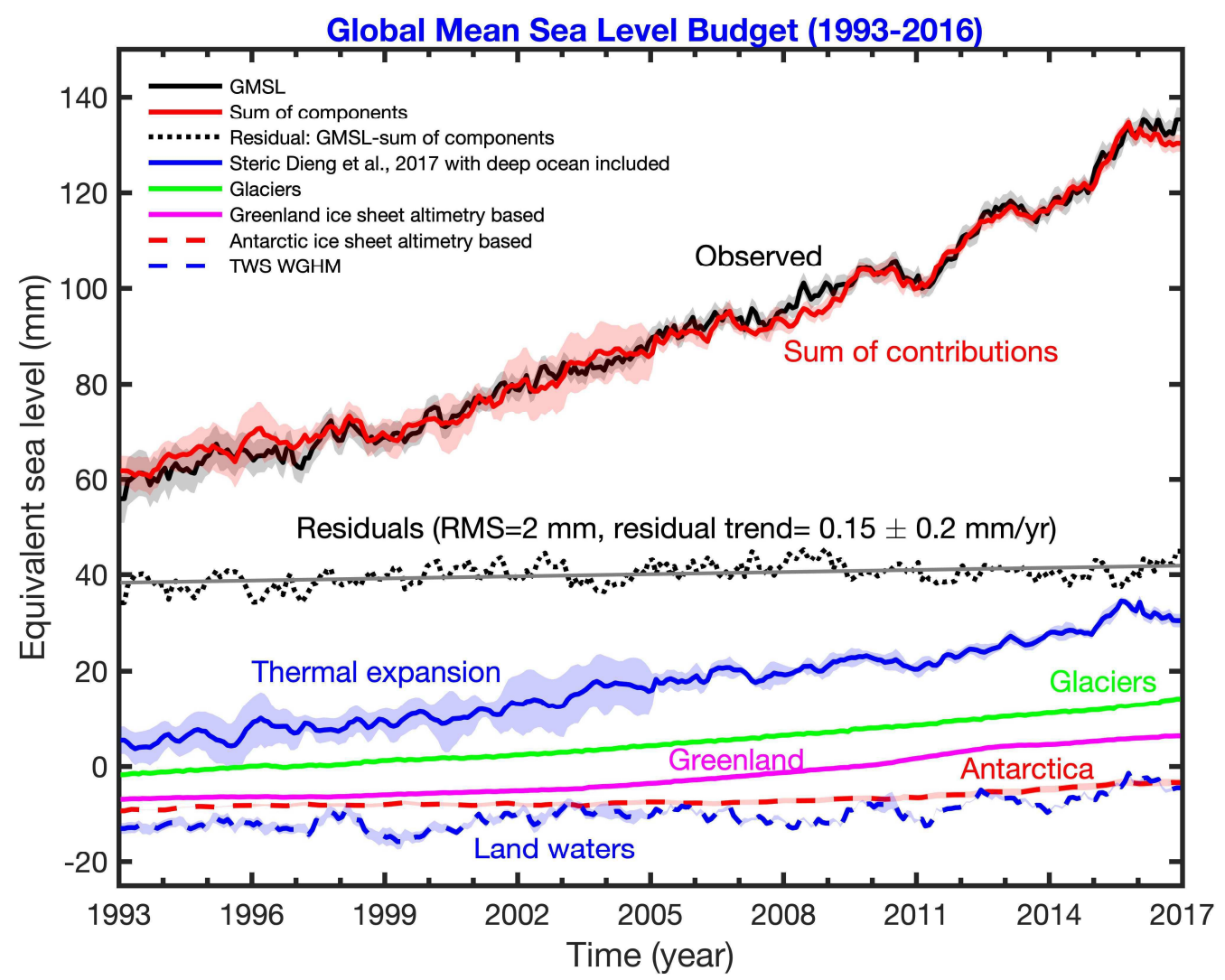

Fig.3: Sea level budget over 1993-2016. The individual contributions are shown at the bottom of the panel. The altimetry-based sea level and sum of contributions are shown by the black and red curves respectively. The black dotted curve is the difference between observed sea level and sum of contributions (Source: ESA Sea Level Budget Closure project, Horwath et al., 2020;http://www.esa-sealevel-cci.org). 
small-scale processes superimpose to the global mean and regional sea level components, and can make coastal sea level substantially different from open ocean sea level rise. For example, changes in small-scale currents, as well as freshwater input in river estuaries, can modify the density structure of sea waters, hence coastal sea level. Changes in wind, waves, shelf bathymetry, along-shore and cross-shore sediment transport, vertical land motions, land use change, and urbanization are additional forcing factors able to modify sea level variations in the coastal zone. Unlike global mean and regional sea level measured by satellite altimetry missions, coastal sea level changes remain poorly known. Coastal zones are indeed highly under-sampled by tide gauges and currently un-surveyed (within 15 kilometers to the coast) by conventional altimetry missions because of land contamination on the radar signal. However, dedicated reprocessing of the data from these missions now allow to estimate sea level change very close to the coast. Figure 4 shows coastal sea level trends based on the reprocessing of Jason-1, Jason-2 and Jason-3 altimetry missions over 20022018 (Climate Change Initiative Coastal Sea Level Team, 2020). The figure indicates that at a significant number of sites, coastal sea level rise over the study period is in general positive (with a few exceptions), with values as high as $4-5 \mathrm{~mm} / \mathrm{yr}$ in some regions. This is particularly the case in the northern and eastern parts of the Indian ocean (around Indonesia for the latter).

In Fig. 5 are presented differences in sea level trends between the first $2-4 \mathrm{~km}$ from the coast at a number of coastal sites and open ocean changes (at $15 \mathrm{~km}$ from the coast).

In most places, Fig.5 indicates that no significant difference (within $\pm 1 \mathrm{~mm} / \mathrm{yr}$ ) is noticed between the open ocean and the coastal zone. However, this is not always true. At a few sites, we observe a larger trend close to the coast than offshore, but this increase is modest, of 1-2 mm/yr only, and possibly not significant in view of the trend uncertainties. In a few cases also, we note a decrease at the coast. The coastal processes causing such behaviors are not yet fully understood.

\section{Future Sea Level Changes}

In the recently published (September 2019) special report on the oceans and the cryosphere (SROCC, 2019) from the Intergovernmental Panel on Climate change (IPCC), projections of future sea level rise based on ensemble means of processbased climate models indicate that at the end of the $21^{\text {st }}$ century, global mean sea level should be on average, higher than today in the range $\sim 40 \mathrm{~cm}$ to $\sim 85 \mathrm{~cm}$, depending on the radiative forcing scenario. $40 \mathrm{~cm}$ correspond to a climate scenario that fulfills the 2015 Paris Agreement, i.e., a $2^{\circ} \mathrm{C}$ target for the global mean Earth temperature in 2100 (compared to pre-industrial). This scenario would require drastic reduction of GHG emissions in the coming 2-3 decades and zero emission around 2070. $85 \mathrm{~cm}$ correspond to a high warming scenario, more or less following current GHG emissions. In this scenario, a global mean sea level elevation of +1 m compared to year 2000 is not excluded. In the high warming scenario (RCP 8.5), ocean warming, glaciers melting and Greenland and Antarctica ice sheet mass loss contribute by $\sim 37 \%, 23 \%, 18 \%$ and $17 \%$ respectively, the remaining $5 \%$ being attributed to land water storage change. Summing the contributions of glaciers and ice

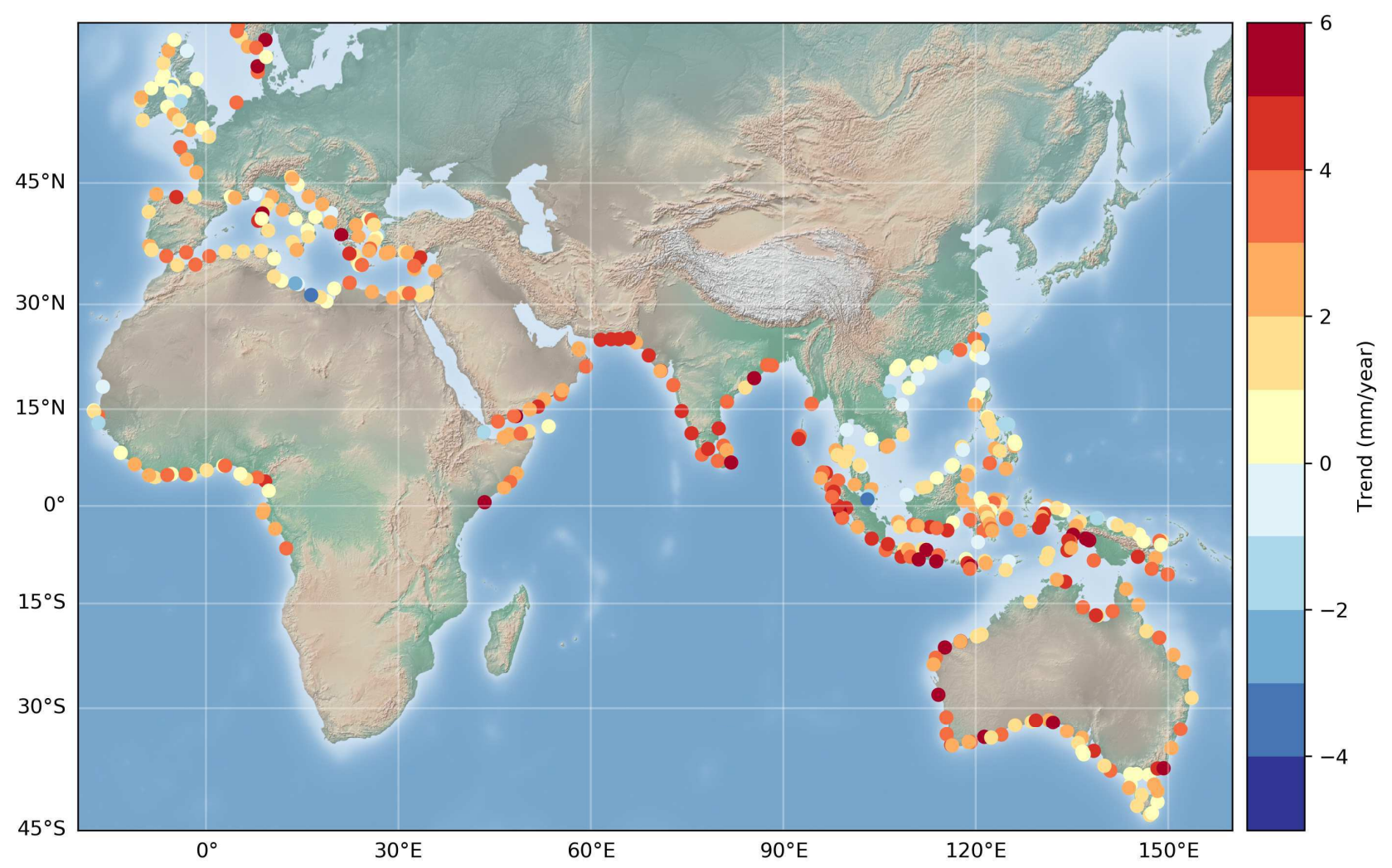

Fig.4. Coastal sea level trends (mm/yr) over 2002-2018 at a number of sites based on reprocessing of altimetry data of the Jason-1,2 and 3 missions (Source: the ESA Climate Change Initiative, coastal sea level project, 2020). 


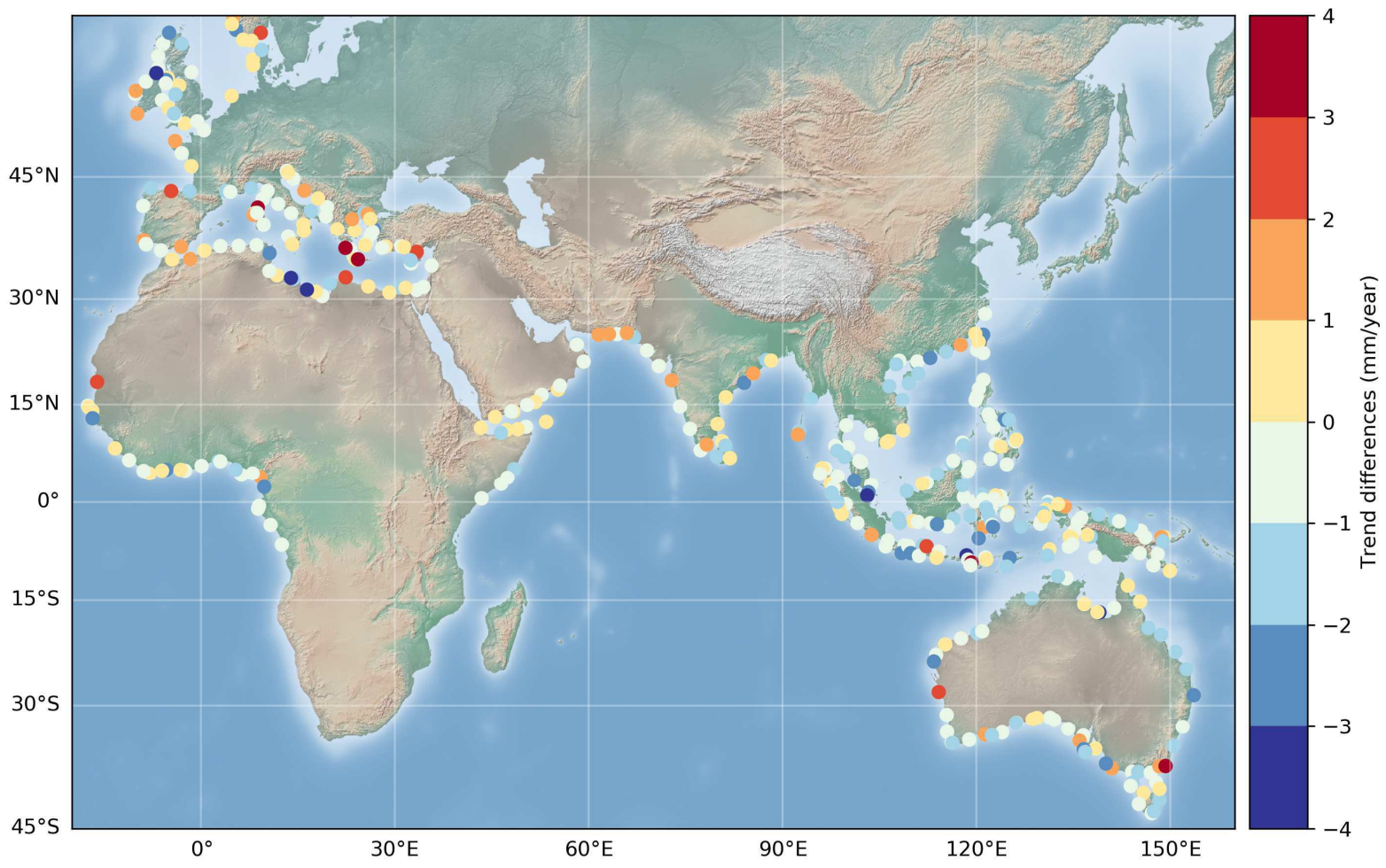

Fig.5. Differences in sea level trends between the coast and offshore (15 km from the coast in the open ocean). Light blue and yellow correspond to no significant differences. Orange-red/blue dots correspond to coastal trend increase/decrease at the coast (Source: the ESA Climate Change Initiative, coastal sea level project, 2020).

sheets shows that land ice melt contributes by nearly $60 \%$. It has been recently suggested that account for a new type of ice sheet instability in Antarctica (as yet unobserved), would lead to $\sim 1 \mathrm{~m}$ global mean sea level rise by 2100 for Antarctica alone. But such a possibility is still controversial.

\section{Synthesis}

Today, sea level rise is one of the best indicators of climate change. This is because it integrates changes occurring in the Earth's climate system in response to unforced climate variability, as well as natural and anthropogenic forcing factors. These factors include the net contribution of ocean warming, land ice melt, and changes in water storage in continental river basins. For some components, changes that occur over time are directly reflected in the global mean sea level time series.

Measuring sea level rise and understanding its causes has considerably improved in the recent years, essentially because new in situ and remote sensing observations have become available. Sea level is presently rising at a sustained rate of more than $3 \mathrm{~mm} / \mathrm{yr}$ and is accelerating. These observations are of major importance for process understanding and validation of climate models developed to project future changes. It is indeed almost certain that sea level rise will continue in the future decades and centuries because of expected continuing global warming, thereby affecting a large number of world coastal regions. Sustained observations of sea level changes, as well as observations of the various factors that cause these changes, are of high priority in climate change research in order to provide improved sea level projections from global to local scales (Cazenave et al., 2019). In the coastal zones, sea level observations and projections will provide invaluable information to decision-makers in charge of developing adaptation and mitigation strategies to face climate and environmental risks, in particular sea level rise.

Laboratoire d'Etudes en Géophysique

Anny CAZENAVE et Océanographie Spatiales (LEGOS) CNES \& Observatoire Midi-Pyrénées 18 Av. E. Belin, 31401 Toulouse

cedex 9, France

E-mail: anny.cazenave@gmail.com

\section{References}

Cazenave A., Palanisamy H. and Ablain M. (2018) Contemporary sea level changes from satellite altimetry: What have we learned? What are the new challenges? Advances in Space Research, DOI: 10.1016/j.asr.2018.07.017, published online 27 July 2018.

Cazenave, A. and Coauthors (2019) Observational requirements for long-term monitoring of the global mean sea level and its components over the altimetry era. Frontiers in Marine Science, 6, 582. DOI: $10.3389 /$ fmars.2019.00582.

Climate Change Initiative Coastal Sea Level Team. A database of coastal sea level anomalies and associated trends from Jason satellite altimetry from 2002-2018, Nature Scientific Data, submitted, 2020.

Friedlingstein P. et al., (2019) The Global Carbon Budget 2019, Earth Syst. Sci. Data, 11, 1783-1838, DOI:10.5194/essd-11-1783-2019.

Horwath, M., and Coauthors, (2020) ESA Climate Change Initiative (CCI) Sea Level Budget Closure (SLBC_cci) Summary Report D4.2. Version 1.0, 09.03.2020. 
Special Report on the Ocean and Cryosphere in a Changing Climate (SROCC), IPCC (2019) [H.-O. Portner, D.C. Roberts, V. MassonDelmotte, P. Zhai, M. Tignor, E. Poloczanska, K. Mintenbeck, A. Alegriìa, M. Nicolai, A. Okem, J. Petzold, B. Rama, N.M. Weyer (eds.)].

Legeais J.F., et al., (2018) An improved and homogeneous altimeter sea level record from the ESA Climate Change Initiative. Earth Syst. Sci. Data, 10, 281-301, DOI: 10.5194/essd-10-2812018.

Nerem, R. S., B. D. Beckley, J. Fasullo, B. D. Hamlington, D. Masters and G. T. Mitchum (2018) Climate Change Driven Accelerated Sea Level Rise Detected In The Altimeter Era. Proc. Nat. Acad. Sci., 15, 2022-2025, DOI: doi.org/10.1073/pnas.171731 2115.

von Schuckmann, K. and Coauthors (2016) An imperative to monitor Earth's energy imbalance, Nature Climate Change, 6, 138-144, DOI: $10.1038 /$ nclimate2876.

WCRP Global Sea Level Budget Group (2018) Global sea level budget, 1993-present, Earth System Science Data, 10, 1551-1590. DOI: 10.5194/essd-10-1551-2018.

\section{Further reading/literature}

The Earth Cryosphere and Sea Level Change, L. Bengtsson, S. Koumoutsaris, R.-M. Bonnet, E.-A. Herland, P. Huy-brechts, O.M. Johannessen, G. Milne, J. Oerlemans, A. Ohmura, G. Ramstein, P. Woodworth (Eds.), SSSI Vol. 40, ISBN 978-94-007-2062-6, 2011.

Integrative Study of Mean Sea Level, A. Cazenave, N. Champollion, F. Paul and J. Benveniste (Edts), SSSI Vol. 58, ISBN 978- 3-31956490-6, 2017.

Applications of satellite altimetry over oceans and land surfaces, Stammer D. \& Cazenave A. edts., CRC Press, Taylor \& Francis, 517 pages, ISBN 978-1-4987-4345-7, 2018.

Understanding the Relationship between Coastal Sea Level and LargeScale Ocean Circulation, R. Ponte, B. Mey-ssignac, C. Domingues, D. Stammer, A. Cazenave, T. Lopez (Eds.), SSSI 75, in press, 2020. 